Navigation Physics 1(2) (2019)
Navigation Physics
Journal of Physics Education

\title{
Pengembangan Multimedia Berbasis Salingtemas untuk Pembelajaran IPA Tema 1 di Kelas IV Sekolah Dasar
}

\author{
Fitrian Prila Wardani ${ }^{1 *}$, Dita Puspitawedana ${ }^{2}$, dan Pebri Isnawati ${ }^{3}$ \\ ${ }_{1,2,3}$ STKIP Darussalam Cilacap \\ E-mail: fitrianprilawardani@gmail.com¹, puspitadita23@gmail.com², febryisnawati91@gmail.com
}

\begin{tabular}{|c|c|}
\hline Info Artikel & Abstract \\
\hline $\begin{array}{l}\text { Sejarah Artikel: } \\
\text { Diterima Desember } 2019 \\
\text { Disetujui Desember } 2019 \\
\text { Dipublikasikan Desember } 2019 \\
\text { Keywords: } \\
\text { Multimedia, Salingtemas, Pembelajaran } \\
\text { IPA SD, Tema 1 }\end{array}$ & $\begin{array}{l}\text { This research is a Research Development (R\&D) using design research. } \\
\text { The purpose of this study is to develop and know the feasibility of } \\
\text { Salingtemas-based multimedia (Science, Environment, Technology, and } \\
\text { Society) for learning science theme } 1 \text { in grade IV of Elementary School. } \\
\text { The stage carried out in this research is in the initial stages resulting in a } \\
\text { description of the need for multimedia development. At the development } \\
\text { stage begins by designing solutions to problems found in the initial stages. } \\
\text { The evaluation phase is carried out an evaluation (validation test and } \\
\text { product trial) to determine the feasibility and improve the product that has } \\
\text { been developed. The subjects of the trial are teachers and fourth grade } \\
\text { students in the SD Negeri } 2 \text { Cihonje, Gumelar subdistrict, Banyumas } \\
\text { district. Testing the feasibility of multimedia based on Salingtemas is } \\
\text { carried out with an assessment by experts both in terms of material and } \\
\text { media that have been developed. The results show that the development of } \\
\text { multimedia based on Salingtemas for natural science learning theme } 1 \text { in } \\
\text { class IV Elementary School reach an average percentage of } 89,5 \% \text { for } \\
\text { media expert judgment, } 91 \% \text { for material expert assessment and } 85 \% \text { for } \\
\text { users, so it can be stated worthy. }\end{array}$ \\
\hline
\end{tabular}

How to Cite: Wardani, F.P., Puspitawedana, D., \& Isnawati, P. (2019). Pengembangan Multimedia Berbasis Salingtemas untuk Pembelajaran IPA Tema 1 di Kelas IV Sekolah Dasar, Navigation Physics, 1(2): 33-40

\section{PENDAHULUAN}

Media pembelajaran dapat digunakan untuk menyalurkan pesan (bahan pembelajaran), sehingga minat, pikiran, dan perasaan siswa dalam kegiatan belajar untuk mencapai tujuan belajar (Santyasa, 2007: 3). Salah satu media pembelajaran yang banyak digunakan pada saat ini adalah media pembelajaran berbasis komputer. Multimedia dapat diartikan sebagai lebih dari satu media yang berupa grafik, teks, suara, video, dan animasi (Arsyad: 2007). Penggabungan lebih dari satu media ini merupakan satu kesatuan yang secara bersama-sama menampilkan informasi, pesan, atau isi pelajaran. Berdasarkan beberapa pendapat ahli tersebut dapat disimpulkan bahwa multimedia pembelajaran merupakan alat bantu pembelajaran berbasis komputer yang menggunakan dua atau lebih jenis media antara lain gambar, animasi, teks dan suara yang digunakan untuk menyajikan atau mengajarkan suatu topik mata pelajaran (Kustandi, 2011). Mulitimedia memiliki peran untuk memberikan rangsangan dan persepsi yang sama dari pengalaman maupun karakter siswa yang berbeda pada pembelajaran IPA di Sekolah Dasar (SD). Telah diketahui bahwa pembelajaran IPA di SD menekankan pada prinsip pemahaman dengan harapan siswa dapat mengaplikasikannya pada lingkungan sekitar. Pada proses pembelajaran IPA SD, siswa diharapkan dapat memiliki kemampuan memandang sesuatu secara terintegrasi dengan memperhatikan unsur sains, lingkungan, teknologi dan masyarakat yang biasa disebut dengan Salingtemas (Sains, Lingkungan, Teknologi, dan Masyarakat).

Salingtemas merupakan pembelajaran yang dimaksudkan untuk membelajarkan siswa agar mengetahui bahwa ilmu (sains) dapat menghasilkan teknologi untuk memecahkan masalah yang ada di lingkungan sehingga hasilnya bermanfaat bagi masyarakat. Salingtemas dapat meningkatkan keterkaitan 
siswa terhadap sains, karena dapat menjadikan konsep abstrak menjadi lebih konkrit (Yoruk, N., I. Morgil, \& N. Secken, 2010). Salingtemas diimplementasikan agar pada proses pembelajaran IPA di SD tidak hanya mempelajari konsep tetapi juga membantu siswa memahami sains, perkembangannya dan bagaimana perkembangan sains dapat mempengaruhi lingkungan, teknologi dan masyarakat secara timbal balik. Tujuan dari pendekatan Salingtemas adalah agar siswa mampu menghubungkan realitas sosial dengan topik pembelajaran di dalam kelas, mampu menggunakan berbagai jalan/prespektif untuk menyikapi berbagai isu/situasi yang berkembang di masyarakat berdasarkan pandangan ilmiah, dan mampu menjadikan dirinya sebagai warga masyarakat yang memiliki tanggungjawab sosial.

IPA merupakan ilmu yang berkaitan alam secara sistematis dan bukan hanya pengetahuan tentang fakta, prinsip, konsep saja melainkan proses penemuan. IPA sebagai ilmu yang sistematis dan tersusun secara teratur, berlaku umum, dan berupa kumpulan data ilmiah, agar mampu mengkomunikasikan dalam kehidupan sehari-hari ${ }^{[7]}$. Pengalaman pembelajaran sebagai upaya pengembangan keterampilan proses dan sikap ilmiah. Pelaksanaan pembelajaran IPA bertujuan untuk memberikan pengalaman belajar secara langsung melalui penggunaan dan pengembangan keterampilan proses dan sikap ilmiah. Pada proses pembelajaran IPA di SD, siswa diharapkan dapat memiliki kemampuan memandang sesuatu secara terintegrasi dengan memperhatikan unsur sains, lingkungan, teknologi dan masyarakat. Sehingga dapat membantu siswa dalam memahami materi IPA di kelas dengan menghubungkan realita sosial dengan materi yang dipelajari.

Penggunaan multimedia berbasis Salingtemas di SD kecamatan Gumelar kabupaten Banyumas oleh guru dalam proses pembelajaran masih sedikit. Pembelajaran yang dilakukan oleh guru pada umumnya metode pembelajaran yang bersifat monoton dan kurang variatif menggunakan media pembelajaran. Pembelajaran yang dilakukan oleh guru belum mengaitkan antara sains, lingkungan, teknologi dan masyarakat. Hal tersebut berakibat pada berkurangnya pemahaman, motivasi dan ketertarikan siswa dalam pembelajaran IPA khususnya pada Tema 1.

Berdasarkan uraian tersebut rumusan masalah dari penelitian ini adalah adalah (1) bagaimana pengembangan multimedia berbasis Salingtemas untuk pembelajaran IPA Tema 1 di kelas IV Sekolah Dasar?, (2) bagaimana kelayakan multimedia berbasis Salingtemas untuk pembelajaran IPA Tema 1 di kelas IV Sekolah Dasar yang dikembangkan?

Berdasarkan rumusan masalah yang telah dikemukakan, tujuan dari penelitian ini adalah (1) mengembangkan multimedia berbasis untuk pembelajaran IPA Tema 1 di kelas IV Sekolah Dasar, (2) mengetahui kelayakan multimedia berbasis Salingtemas untuk pembelajaran IPA Tema 1 di kelas IV Sekolah Dasar yang dikembangkan.

Berdasarkan hal tersebut maka peneliti merasa perlu untuk mengembangkan sebuah teknologi tepat guna berupa multimedia pembelajaran IPA yang dipadukan dengan pembelajaran berbasis Salingtemas. Multimedia berbasis Salingtemas untuk pembelajaran IPA di kelas IV SD yang dikemas dalam compact disc $(\mathrm{CD})$ berbentuk sajian yang memadukan tulisan, gambar, animasi dan suara yang dirangkai dalam satu kesatuan, diberi efek gerak, berisi materi. Perangkat lunak yang dapat digunakan untuk membuat multimedia diantaranya Adobe Flash Professional CS5.5, Any Video Converter dan MediaHuman Audio Converter. Multimedia berbasis Salingtemas adalah media komunikasi visual yang mempunyai kekuatan untuk menyampaikan informasi secara menarik, efektif, mudah dipahami dan dapat memberikan rangsangan yang sama sehingga dalam pembelajaran IPA siswa dapat mengintegrasikan unsur sains, lingkungan, teknologi dan manfaatnya untuk masyarakat.

\section{METODE PENELITIAN}

\section{A. JENIS PENELITIAN}

Penelitian ini merupakan penelitian pengembangan atau Research and Development (R\&D) dengan menggunakan penelitian desain (design research) yang dikemukakan oleh Plomp (2013: 19). Model Plomp dipilih karena model ini dianggap sederhana dan praktis untuk penelitian pengembangan media pembelajaran ini. Adapun tahapan dalam model pengembangan Plomp (2013: 19)yaitu.

1. Preliminary research (Tahap Penelitian Awal)

Pada tahap ini meliputi analisis konteks, tinjauan literatur, dan pengembangan kerangka konseptual atau teoritis untuk penelitian. Hal yang menjadi unsur penting pada tahapan ini adalah memahami masalah, pengumpulan informasi, menganalisis informasi yang diperoleh, dan menyususn kegiatan selanjutnya.

2. Development or prototyping phase (tahap pengembangan)

Pada tahap ini terdiri dari literasi, masing-masing menjadi siklus penelitian kecil dengan evaluasi formatif sebagai hal yang paling penting. Kegiatan yang dilakukan yaitu merancang solusi dari 
permasalahan yang ditemukan pada tahapan awal. Dari solusi tersebut akan dihasilkan produk awal atau biasa disebut prototype yang nantinya akan diujikan dilapangan.

3. Assessment phase (tahapan penilaian)

Pada tahap ini meliputi kegiaatn menyimpulkan apakah solusi memenuhi spesifikasi yang telah ditentukan atau belum serta melakukan evaluasi untuk memperbaiki produk yang sudah dikembangkan.

\section{B. BAGAN ALIR PENELITIAN}

Bagan alir pada penelitian ini ditunjukkan oleh Gambar 1.

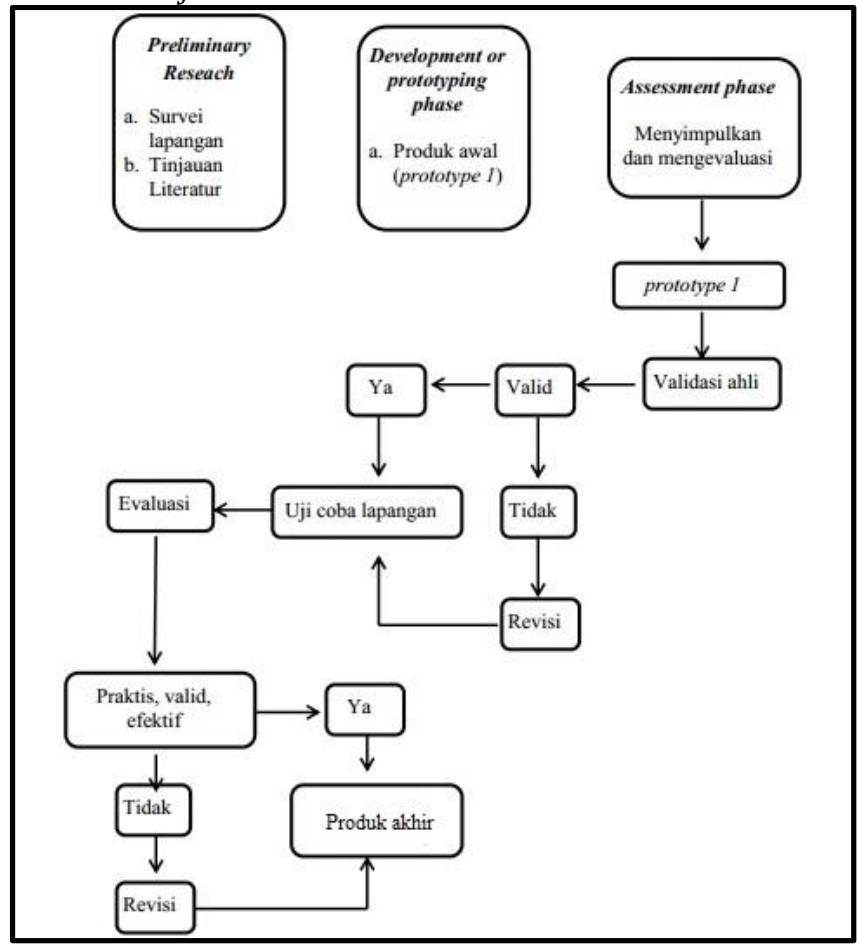

Gambar 1. Diagram alir penelitian

C. Subjek Penelitian

Subjek dalam penelitian ini adalah siswa kelas IV SD, praktisi yaitu guru kelas IV SD, ahli materi IPA SD dan ahli multimedia.

D. Waktu Dan Tempat Penelitian

Penelitian ini dilakukan di kelas IV SD Negeri 2 Cihonje, kecamatan Gumelar, kabupaten Banyumas. Penelitian ini dilaksanakan pada tanggal bulan November 2019.

E. Teknik Pengambilan Data

Data dalam penelitian ini diperoleh dengan penilaian ahli dan siswa. Instrumen yang digunakan adalah instrumen penilaian ahli materi, penilaian ahli media, dan penialain pengguna.

F. Teknik Analisis Data

Teknik analisis data yang digunakan dalam penelitian ini adalah kuantitatif dan kualitatif yang diperoleh dari hasil penilaian ahli dan pengguna. Data yang diperoleh selanjutnya dianalisis dengan tujuan untuk mengetahui kelayakan multimedia. Hasil analisis data digunakan sebagai dasar untuk merevisi produk multimedia yang dikembangkan. Persentase dari penilaian ahli dapat dicari menggunakan persamaan (1).

$$
P(s)(\%)=\frac{s}{N} \times 100 \%
$$

Keterangan:

$$
\begin{aligned}
& P(s)=\text { persentase kelayakan }(\%) \\
& s \quad=\text { skor yang diobservasi } \\
& N=\text { skor maksimum }
\end{aligned}
$$


Data yang dikumpul dianalisis dengan teknik analisis deskriptif yang diungkapkan dengan distributor skor dan persentase. Setelah dijadikan persentase selanjutnya mendeskripsikan dan mengambil kesimpulan tentang masing-masing indikator. Kriteria validasi yang digunakan pada penelitian ini ditunjukkan pada tabel 1.

Tabel 1. Interval kriteria penilaian

\begin{tabular}{ccc}
\hline No. & Interval & Kriteria kualitatif \\
\hline 1. & $0 \%-25 \%$ & Tidak baik \\
2. & $26 \%-50 \%$ & Kurang baik \\
3. & $51 \%-75 \%$ & Cukup baik \\
4. & $76 \%-100 \%$ & Baik \\
\hline
\end{tabular}

\section{HASIL DAN PEMBAHASAN}

Penelitian ini telah berhasil mengembangkan produk multimedia berbasis Salingtemas untuk pembelajaran IPA Tema 1 di kelas IV SD. Multimedia berbasis Salingtemas untuk pembelajaran IPA Tema 1 di kelas IV SD ini menggunakan perangkat lunak Adobe Flash Professional CS5.5, Any Video Converter dan Media Human Audio converter. Sasaran multimedia berbasis Salingtemas untuk pembelajaran IPA Tema 1 di kelas IV SD adalah siswa dan guru untuk membantu menjelaskan materi IPA Tema 1. Materi IPA kelas IV pada Tema 1 Indahnya Kebersamaan adalah sumber bunyi dan indera pendengaran (telinga).

Hasil pengembangan multimedia berbasis Salingtemas untuk pembelajaran IPA Tema 1 di kelas IV SD dapat dideskripsikan sebagai berikut:

1. Tampilan awal

Tampilan awal pada multimedia berbasis Salingtemas untuk pembelajaran IPA Tema 1 di kelas IV SD berisi tampilan loading, logo perangkat lunak yang digunakan, serta judul multimedia berbasis Salingtemas untuk pembelajaran IPA Tema 1. Salah satu tampilan awal pada multimedia ditunjukkan oleh Gambar 2.

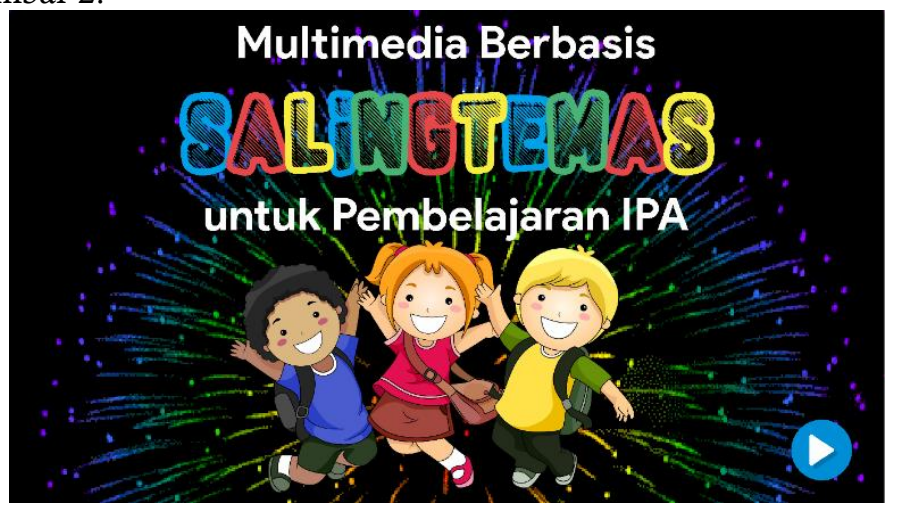

Gambar 2. Tampilan awal berupa tampilan judul multimedia

2. Tampilan pengenalan multimedia

Merupakan bagian pengenalan multimedia berbasis Salingtemas untuk pembelajaran IPA Tema 1 di kelas IV SD. Tampilan pengenalan multimedia ditunjukkan oleh Gambar 3.

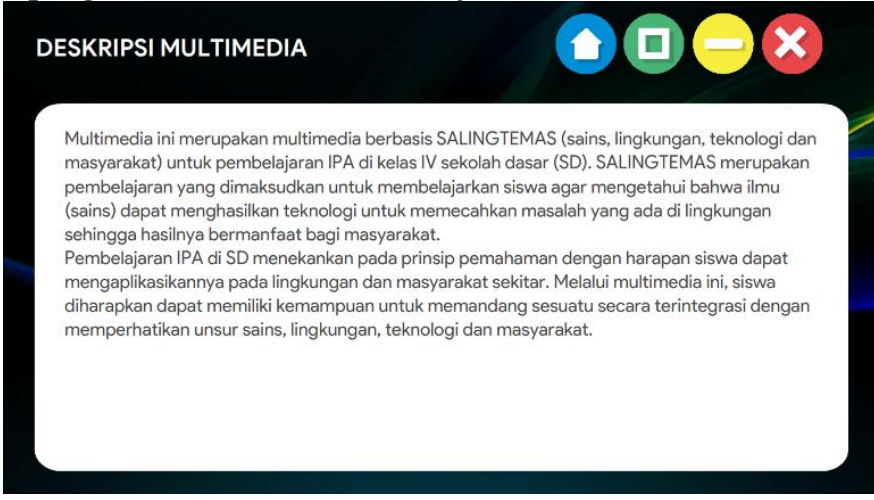

Gambar 3. Tampilan pengenalan multimedia 
3. Tampilan kompetensi inti (KI) dan kompetensi dasar (KD)

Pada bagian ini menampilkan standar kompetensi dan kompetensi dasar dari materi IPA Tema 1 kelas IV SD. Dalam kurikulum 2013 KD IPA diklasifikasikan kedalam empat KI. Tampilan KI dan KD ditunjukkan oleh Gambar 4.

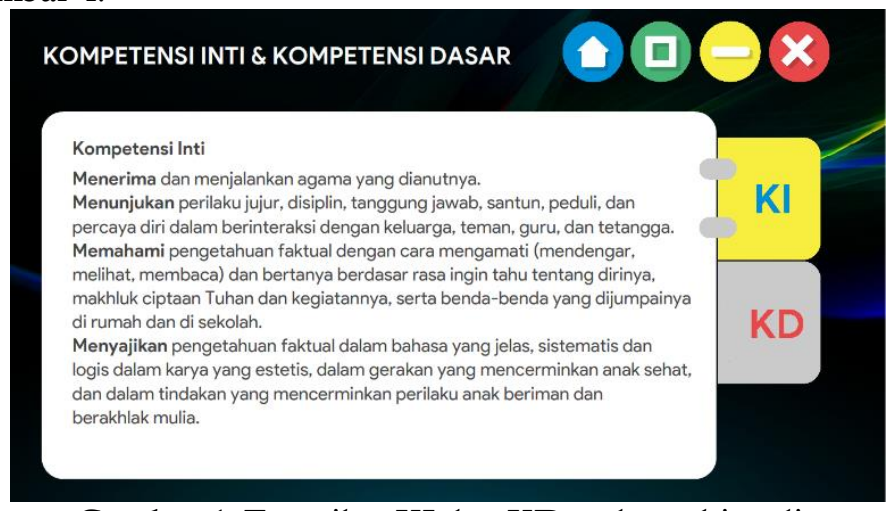

Gambar 4. Tampilan KI dan KD pada multimedia

4. Tampilan menu

Tampilan menu pilihan dari multimedia berbasis Salingtemas untuk pembelajaran IPA Tema 1 di kelas IV SD berisi pilihan untuk menuju ke materi, soal latihan, dan tombol untuk menutup multimedia berbasis Salingtemas untuk pembelajaran IPA Tema 1 di kelas IV SD. Tampilan menu ditunjukkan oleh Gambar 5.

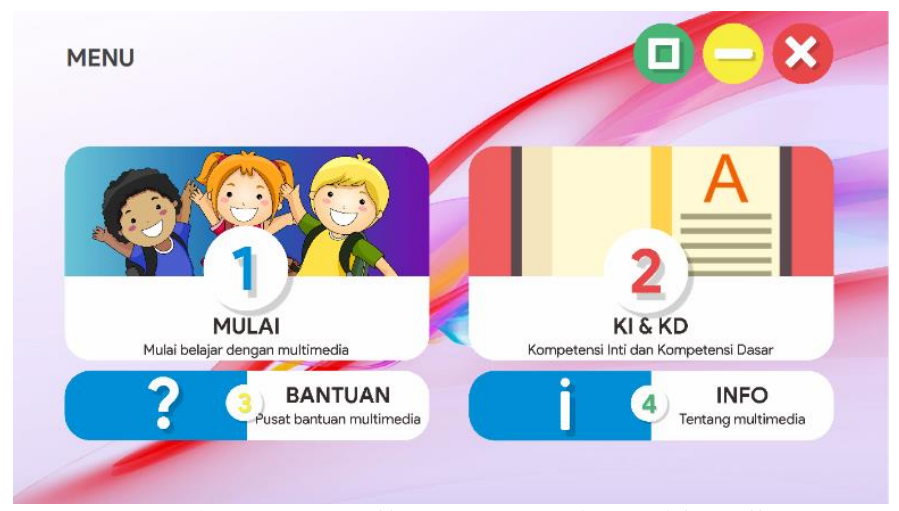

5. Tampilan pretest dan postest

Gambar 5. Tampilan menu pada multimedia

Pada bagian ini menampilkan masing-masing sepuluh (10) soal pretest dan postest. Soal pretest disusun untuk mengetahui sejauh mana siswa memahami materi bunyi dan indera pendengaran (telinga) sebelum dan sesudah penyampaian materi. Tampilan pretest ditunjukkan oleh Gambar 6 .

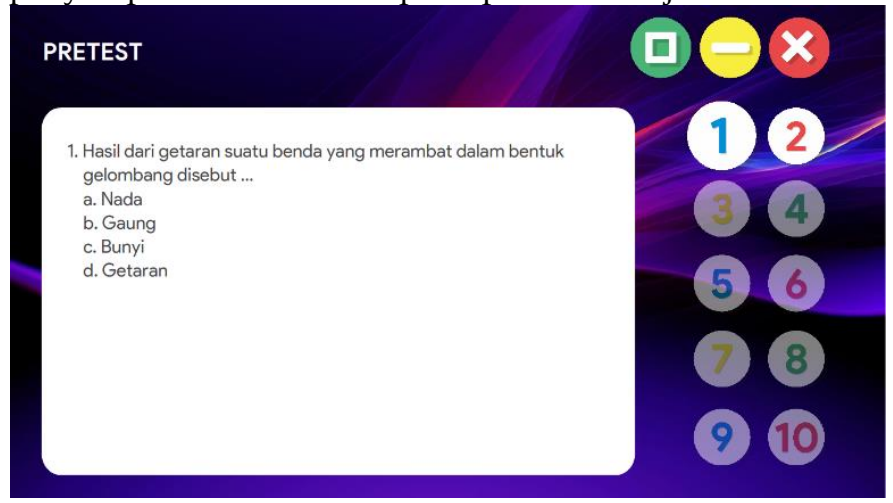

Gambar 6. Tampilan pretest pada multimedia

6. Materi IPA Tema 1 kelas IV SD

Menampilkan inti dari multimedia berbasis Salingtemas untuk pembelajaran IPA Tema 1 di kelas IV SD yang berisi penyampaian seluruh materi IPA Tema 1 kelas IV SD. Materi IPA Tema 1 kelas IV SD 
dalam Kurikulum 2013 mempelajari tentang bunyi dan indera pendengaran (telinga). Tampilan materi IPA Tema 1 kelas IV SD oleh Gambar 7.

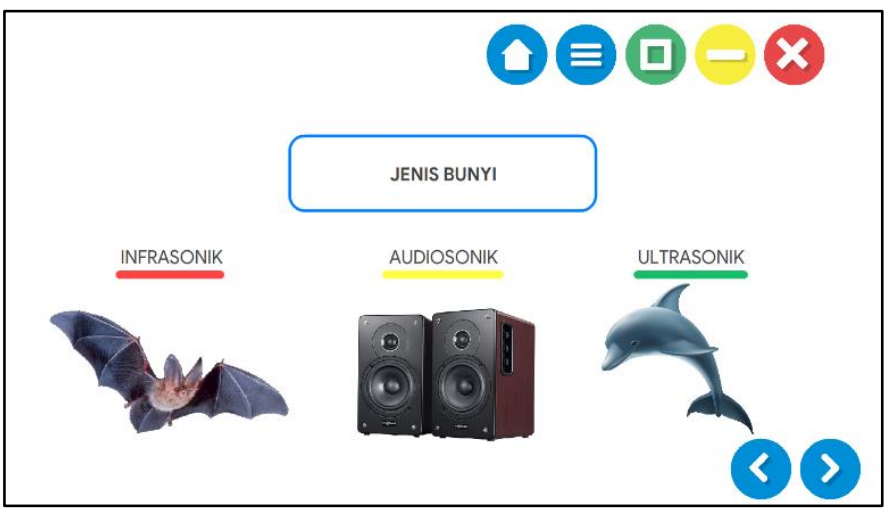

Gambar 7. Tampilan materi IPA Tema 1 pada multimedia

7. Tampilan akhir

Merupakan tampilan penutup multimedia berbasis Salingtemas untuk pembelajaran IPA Tema 1 di kelas IV SD berupa running text yang kemudian media pembelajaran akan mengakhiri dengan sendirinya. Tampilan akhir ditunjukkan oleh Gambar 8.

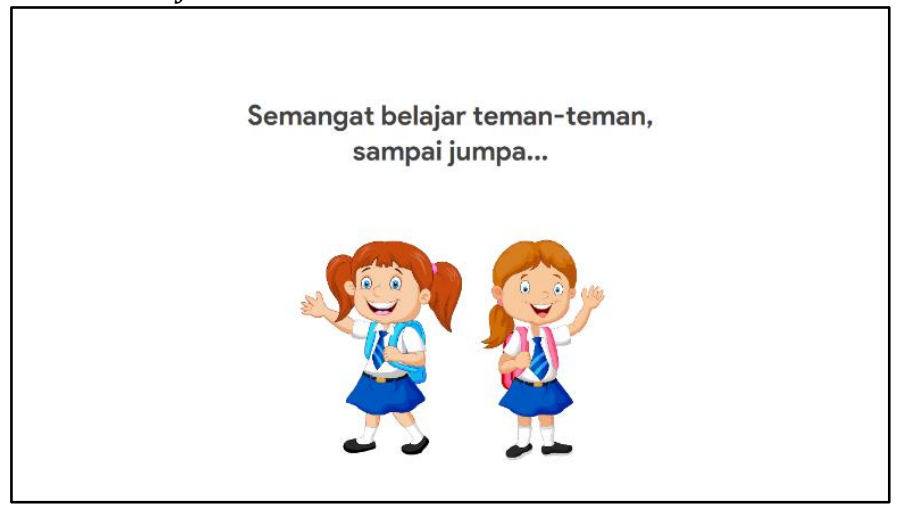

Gambar 8. Tampilan akhir pada multimedia

Berdasarkan langkah uji coba, penelitian ini telah menghasilkan data-data dari para ahli yang bersifat kuantitatif dan kualitatif. Selanjutnya data-data tersebut digunakan untuk melakukan uji kelayakan produk multimedia berbasis Salingtemas untuk pembelajaran IPA Tema 1 di kelas IV SD sebagai landasan perbaikan produk yang akan dikembangkan. Data kuantitatif ahli media terhadap produk multimedia berbasis Salingtemas untuk pembelajaran IPA Tema 1 di kelas IV SD yang dikembangkan menghasilkan presentase rata-rata sebesar $89,5 \%$. Persentase rata-rata sebesar $89,5 \%$ tersebut masuk pada kriteria sangat baik sehingga multimedia berbasis Salingtemas untuk pembelajaran IPA Tema 1 di kelas IV SD dapat dinyatakan layak dari segi media.

Selanjutnya untuk data kuantitatif ahli materi terhadap multimedia berbasis Salingtemas untuk pembelajaran IPA Tema 1 di kelas IV SD menghasilkan presentase rata-rata sebesar 91\%. Persentase ratarata sebesar 91\% tersebut masuk pada kriteria sangat baik sehingga multimedia berbasis Salingtemas untuk pembelajaran IPA Tema 1 di kelas IV SD dapat dinyatakan layak dari segi materi.

Data kuantitatif pengguna terhadap multimedia berbasis Salingtemas untuk pembelajaran IPA Tema 1 di kelas IV SD yang dikembangkan diperoleh dari 20 siswa kelas IV SD Negeri 2 Cihonje di kecamatan Gumelar, kabupaten Banyumas. Hasil persentase rata-rata sebesar 85\%. Hasil persentase tersebut masuk pada kriteria sangat baik sehingga multimedia berbasis Salingtemas untuk pembelajaran IPA Tema 1 di kelas IV SD dapat dinyatakan layak.

Berdasarkan hasil penilaian dari ahli materi, ahli media dan pengguna dapat dilihat bahwa ratarata nilai penilaian termasuk dalam kategori sangat baik sehingga multimedia berbasis Salingtemas untuk pembelajaran IPA Tema 1 di kelas IV SD dapat dinyatakan layak baik dari segi media maupun materi. hal ini tentunya dapat menjawab rumusan masalah yang telah dikemukakan sebelumnya. Presentase rata-rata dari ahli materi, ahli media dan pengguna dapat dilihat pada Tabel 2. 
Tabel 2. Tabel presentase rata-rata dari ahli materi, ahli media dan pengguna

\begin{tabular}{ll}
\hline Ahli & Presentase rata-rata (\%) \\
\hline Materi & $89,5 \%$ \\
Media & $91 \%$ \\
Pengguna & $85 \%$ \\
\hline
\end{tabular}

Berdasarkan tabel 1, presentase rata-rata yang diperoleh dari ahli maateri, ahli media dan pengguna terhadap multimedia berbasis Salingtemas untuk pembelajaran IPA Tema 1 di kelas IV SD dapat disajikan dalam bentuk diagram seperti yang tampak pada Gambar 9.

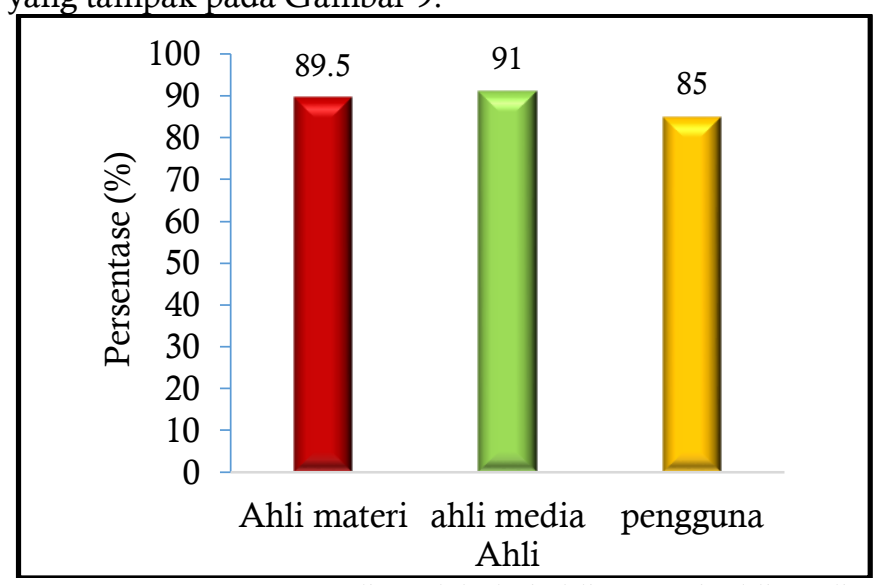

Gambar 9. Diagram presentase rata-rata yang diperoleh dari ahli maateri, ahli media dan pengguna terhadap multimedia berbasis Salingtemas untuk pembelajaran IPA Tema 1 di kelas IV SD

\section{PENUTUP}

Hasil dari penelitian ini merupakan produk multimedia berbasis Salingtemas untuk pembelajaran IPA Tema 1 di kelas IV SD. Multimedia ini telah diuji oleh para ahli dari segi media dan materi, serta telah diujikan pada beberapa pengguna untuk mengetahui apakah multimedia ini layak untuk digunakan siswa dalam pembelajaran. Multimedia ini juga telah dilakukan revisi berdasarkan saran-saran dari para ahli media maupu ahli materi. Hasil uji multimedia menunjukkan bahwa multimedia berbasis Salingtemas untuk pembelajaran IPA Tema 1 di kelas IV SD telah memenuhi syarat kelayakan dengan kriteria baik oleh para ahli sebagai media pembelajaran IPA Tema 1 di kelas IV SD.

\section{UCAPAN TERIMA KASIH}

Peneliti menyampaikan terimakasih kepada ahli media, ahli materi, guru dan siswa SD Negeri 2 Cihonje sebagai yang telah meluangkan waaktu dan tenaga untuk memberikan penilaian terhadap pengguna multimedia berbasis Salingtemas untuk pembelajaran IPA Tema 1 di kelas IV SD. Terimakasih juga peneliti sampaikan kepada anggota tim peneliti yang telah bekerja sama dengan baik selama penelitian ini dilaksanakan. Tidak lupa pula trimakasih untuk semua pihak yang membantu terlaksananya penelitian ini.

\section{DAFTAR PUSTAKA}

Arsyad, A. (2007). Media Pembelajaran. Jakarta: Rajawali Pers

Kustandi, Cecep. (2011). Media Pembelajaran, Manual, dan Digital. Jakarta: Ghalia Indonesia.

Plomp, Tjeerd dan Nieveen, Nienke. 2013. Educational Design Research Part A: An Introduction. The Netherland: SLO, Enschede.

Yoruk, N., I. Morgil, \& N. Secken. 2010. "The Effects of Science, Technology, Society, Environment (STSE) Interactions on Teaching Chemistry". Natural Science Journal, 12(2): 1417-1424 
Santyasa, I Wayan. 2007. "Media Pembelajaran". Jakarta: Universitas Pendidikan Ganesha. (online), (https://www.google.co.id/url?sa=t\&source=web\&rct=j\&ei=DY2gVOe5LdK9uASgsYHQCQ\&ur l=http://file.upi.edu/Direktori/FIP/JUR._PEND._LUAR_SEKOLAH/194704171973032-

MULIATI_PURWASASMITA/MEDIA_PEMBELAJARAN.pdf\&ved $=0 \mathrm{CBwQFjAA \& usg=AF}$ QjCNFQvpyxpGol_BP5Uvl2zuSmNfrnlQ\&sig2=2f2FiorvBysCcrXC4yQVgw. diunduh pada Minggu, 14 Desember 2014 pukul 09.00) 